\title{
How affluence could be good for the environment
}

\author{
Intensive farming means the United States uses less land to feed more people than ever.
}

Sir - A current issue in assessing the environmental effects of economic growth is the per capita use of land in developed versus developing countries. It is often stated that countries with higher incomes demand much more land per person to sustain their higher consumption rates. E. O. Wilson ${ }^{1}$, for example, cites the Worldwide Fund for Nature (WWF) ${ }^{2}$ in asserting that the "ecological footprint" of each person in the United States is 9.6 ha, against a global average of 2.1. From this, Wilson concludes it would require "four more planet Earths" for everyone to live as Americans do.

The accurate, long-running land-use statistics compiled by the US Department of Agriculture Economic Research Service ${ }^{3}$ offer a way to check these assumptions. Using these data, I have calculated per capita US land requirements over time.

Food production represents by far the greatest impact of humans on land worldwide ${ }^{4}$ : about $10 \%$ of the world's 13 billion ha of land is used to grow crops, $25 \%$ for permanent pasture. The continental United States has a land area of 2.8 ha per person at present. Crops are grown on 0.52 ha per capita; pasture, grazed forest land and grazed arable land add an additional 1.17 ha per capita. By comparison, forested lands, parks and wildlife areas total 0.75 ha per capita.

What is most striking is that the total area used for US food production has remained virtually unchanged since 1945. As a result, from 1945 to 1997 per capita cropland use declined by $50 \%$, even as population grew by $90 \%$ and real per capita disposable personal income grew by $177 \%$.

The United States is a substantial net exporter of food. For all high-income countries taken together, average cropland area is 0.4 ha per capita. By comparison, sub-Saharan Africa, which has the world's lowest nutritional status, averages 0.3 ha per capita of cropland and 1.7 ha per capita of grazing land ${ }^{5}$.

Thus, developed nations provide more calories per person, and very substantially more meat and dairy products per person (per capita meat consumption in the United States is 10 times that in subSaharan Africa), while using only slightly more cropland per capita than the poorest countries and less total agricultural land (arable plus grazing) per capita.

The reasons for this are not surprising. Farmers in poorer countries attain much lower yields per ha, largely as a result of very low fertilizer use: $14 \mathrm{~kg}$ of fertilizer per ha of cropland in sub-Saharan Africa versus $114 \mathrm{~kg}$ per ha in the United States is typical $^{5}$. As countries become wealthier, yields increase substantially. Since 1945, US yields per ha of wheat have more than doubled and of maize have more than tripled (ref. 4); the world average yield per ha of maize is now half the US yield. Use of chemical fertilizer and of hybrid and other high-yielding varieties of grains could let developing countries match Western diets with little or no increase in land use.

The growth in urban areas and other uses of land that come with growing affluence add an insignificant amount to land requirements. In the United States, these uses grew from 0.11 ha per capita in 1945 to only 0.13 ha per capita in 1997.

The WWF derived its very high percapita land requirements for developed countries by including in its "ecological footprint" the theoretical amount of forested land that would have to be added to the Earth's surface to absorb $\mathrm{CO}_{2}$ emissions from those countries. But this is an apples-and-oranges comparison; planting forest is but one of many ways that $\mathrm{CO}_{2}$ emissions could be reduced (substituting nuclear energy, for example,

\section{Training to think globally}

Sir — Of the approximately 300 molecularbiology $\mathrm{PhD}$ candidates at Harvard Medical School, only two carry out research on malaria, a disease that kills one child every 40 seconds (see J. Sachs and P. Malaney, Nature 415, 680-685; 2002). An often-cited reason for the lack of interest in pursuing research into diseases prevalent in developing countries is the limited amount of funding allocated to this type of project (with the exception of HIV/AIDS).

However, a more significant factor responsible for this trend could be the nearly complete absence of any discussion related to diseases common in developing countries during the course of our graduate training. For example, we escaped our first year of graduate school without any exposure to current malaria or tuberculosis research.

If those responsible for our training choose to focus almost entirely on diseases most common in the North, such as heart disease or obesity, then the next generation of scientists they train are likely to do the same. Making more effort to teach molecular-biology $\mathrm{PhD}$ candidates about the mechanisms of tuberculosis infection or strategies for malarial vaccine design will cost nothing and will go a long way adds zero land requirements), and in no way constitutes a limit on available land resources of the kind Wilson infers.

In the larger picture, it is worth noting that economic growth in developed countries has become increasingly decoupled from dependence on natural resources. Farm production was $7.2 \%$ of US gross domestic product in 1945 but only $1.1 \%$ in 1997. Paul Ehrlich ${ }^{6}$ has argued that environmental impact is proportional to population times affluence. But as far as land requirements are concerned, it appears to be proportional to population divided by affluence. Stephen Budiansky

Black Sheep Farm, 14605 Chapel Lane, Leesburg, Virginia 20176, USA

1. Wilson, E. O., The Future of Life (Knopf, New York, 2002).

2. Worldwide Fund for Nature, Living Planet Report 2000 (Gland, Switzerland, 2000).

3. US Department of Agriculture, Agricultural Resources and Environmental Indicators, 2000. USDA Economic Research Service, Resource Economics Division (Washington, 2001).

4. Waggoner, P. E., "How much land can ten billion people spare for nature?" Council for Agricultural Science and Technology, Task Force Report No. 121 (Washington, 1994).

5. United Nations Food and Agriculture Organization, FAOSTAT Database; apps.fao.org.

6. Ehrlich, P. R. \& Ehrlich, A. H. The Population Explosion (Simon \& Schuster, New York, 1990) towards creating a new generation of globally minded scientists.

Franklin Huang ${ }^{\star}$, Matt Stremlau $\dagger$

${ }^{\star}$ Washington University School of Medicine, $660 \mathrm{~S}$. Euclid Avenue, St Louis, Missouri 63110, USA †Harvard Medical School and Dana Farber Cancer Institute, Department of Cancer Immunology and AIDS, Jimmy Fund Building 617, 44 Binney Street, Boston, Massachusetts 02115, USA

\section{Hamilton built on work by Haldane and Fisher}

Sir-Olivia Judson's perceptive review of W. D. Hamilton's second volume of Collected Papers (Nature 416, 17-18; 2002) opens with a well-known misapprehension that should be allowed to die. The "discovery of inclusive fitness" was not his, but R. A. Fisher's and J. B. S. Haldane's, to whom Hamilton referred in his papers. It is in both their books, Fisher's The Genetical Theory of Natural Selection (Clarendon, Oxford, 1930) and Haldane's The Causes of Evolution (Longman, London, 1932), as well as their earlier papers and essays.

\section{A. W. F. Edwards}

Gonville and Caius College, Cambridge University, Cambridge CB2 1TA, UK 